\title{
Revealing hidden debottlenecking potential in flare systems on offshore facilities using dynamic simulations - A preliminary investigation
}

\author{
Ana Xiao Outomuro Somozas ${ }^{\mathrm{a}}$, Rudi P. Nielsen ${ }^{\mathrm{a}}$, Marco Maschietti ${ }^{\mathrm{a}}$, \\ Anders Andreasen ${ }^{\mathrm{b}, *}$, \\ ${ }^{a}$ Aalborg University, Department of Chemistry and Bioscience, Niels Bohrs Vej 8, \\ DK-6700 Esbjerg, Denmark \\ ${ }^{b}$ Ramboll Energy, Field Development, Studies and FEED, Bavnehøjvej 5, DK-6700 \\ Esbjerg, Denmark
}

\begin{abstract}
Three flare systems are modeled and total plant depressurization is investigated using dynamic simulations in order to access the debottlenecking potential. Usually steady-state simulation of the flare network is used for sizing and rating of the flare system. By using dynamic simulations effects from line packing in the flare system can be studied. The results show that peak flow during a dynamic simulations is significantly lower than the peak flow used in a steady-state case. The three systems investigated span a wide range in flare system size, both in terms of number of process segments disposing into the flare network, in terms of peak design rate and the flare network pipe dimensions and total hold-up volume. Generally, it is observed that the larger the flare system, the larger debottlenecking potential.
\end{abstract}

Keywords: Emergency depressurization, Flare network, Debottlenecking, Dynamic simulation

\footnotetext{
${ }^{*}$ Corresponding author

Email address: anra@ramboll.com (Anders Andreasen)
} 


\section{Introduction}

The flare system is a pivotal part of the safety system in process plants handling flammable and hazardous substances. In case of an upset condition causing for instance pressure relief or plant depressurization, the flare system collects vented substances and routes the hazardous fluids to the flare stack. At the flare tip incineration takes places, thereby converting the flammable and hazardous substances to less harmful oxidized products such as $\mathrm{CO}_{2}$ and $\mathrm{H}_{2} \mathrm{O}$. The flare system boundaries are pressure safety valves (PSVs), emergency depressurization valves (EDPs)/blowdown valves (BDVs), spillover valves/pressure control valves (PCVs), in one end, and the flare stack/tip in the other end. From each source, fluid is collected via tail pipes in a network of sub-headers, and headers, via a flare knock-out (KO) drum, to the flare stack and flare tip.

A typical flare system layout for an offshore production facility is shown in Figure 1. The example shows BDVs and PSVs connected to the flare system. Under normal operation, the BDVs and PSVs act as barriers between the hydrocarbon containing process segments/equipment and the flare/disposal

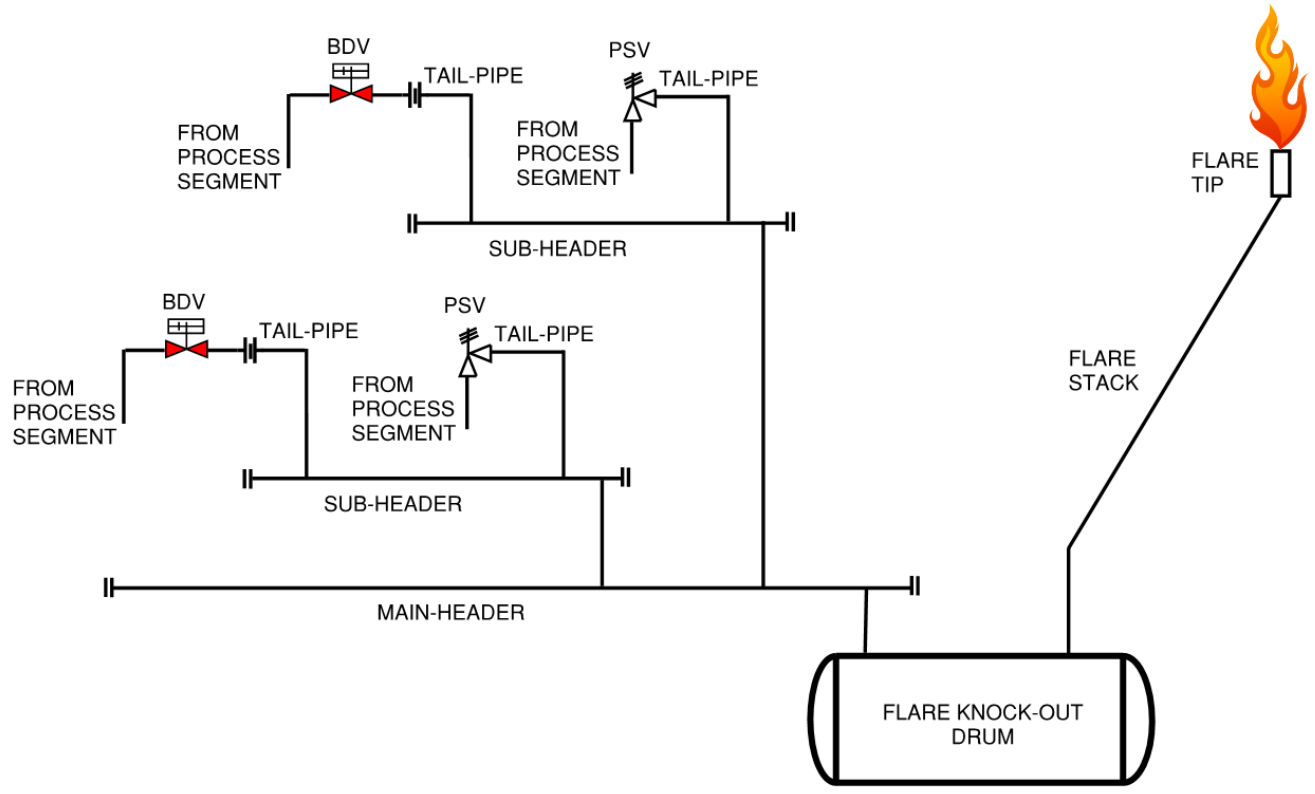

Figure 1: Typical flare system layout on offshore production facility. PCVs/spill-over valves not shown. 


\begin{tabular}{lcccccc}
\hline & \multicolumn{2}{c}{ Tail pipe } & & \multicolumn{2}{c}{ Sub-header/header } \\
\cline { 2 - 3 } \cline { 6 - 7 } Reference & Mach. No. $(-)$ & $\rho v^{2}(\mathrm{~Pa})$ & & Mach. No. $(-)$ & $\rho v^{2}(\mathrm{~Pa})$ \\
\hline API (2014) & N/A & N/A & & N/A & N/A \\
NORSOK (2014) & 0.7 & 200,000 & & 0.6 & 200,000 \\
Total (2012) & 0.7 & 150,000 & & 0.7 & 150,000 \\
Shell (2010) & $<1$ & N/A & & $<1 / 0.7$ & N/A \\
\hline
\end{tabular}

Table 1: Typical design criteria used for sizing of flare network piping according to recognized standards and major oil company standards.

system. In real systems, multiple BDVs and PSVs are connected to subheaders and headers.

The design of the flare system often follows API 521 recommended practice (API, 2014) or similar European standards (ISO, 2006; NORSOK, 2014) or more detailed and/or stringent company guidelines. The flare system is designed for a number of scenarios e.g., pressure relief from one source, or simultaneous reliefs from a number of coincident sources, production flaring and emergency depressurization etc.

Common design criteria for the flare network are summarized in Table 1. Furthermore, during the design of the flare system, it shall also be verified that the backpressure within the flare system does not exceed the design pressure of any part.

API 521 (API, 2014) specifically mentions dynamic simulations as a means for refinement of disposal system design load by e.g., considering that individual relief loads may occur at different times (Nougués et al., 2010) and in general to determine the disposal system hydraulic performance. However, it is common industry practice to determine the flare system hydraulic capacity with a steady-state network solver. Typically, initial peak flows are used for hydraulic sizing of all tail pipes, sub-headers, flare KO drum and flare stack/tip using a commercial steady-state network solver. When evaluating the backpressure and flow rate/velocity in a steady-state approach, these are determined under the assumption that the entire flare system is subjected to the peak flow at once. Especially considering emergency depressurization, a steady-state approach is conservative. Taking the dynamic nature of the depressurization process into account, it can easily be comprehended that downstream segments in the flare system e.g. main header, flare KO drum 
and flare tip will never be subjected to the maximum flow (Chakrabarty et al., 2016). In reality, the initial (peak) flow will rapidly decline owing to the reduction in the upstream pressure and the build up of backpressure. The former is caused by the plant segments being depressurized, whereas the latter is caused by the line packing, i.e., the gradual filling of the entire flare system. These combined effects would effectively smoothen out the peak flow.

It is common practice to use dynamic analysis when considering the depressurization of individual process segments for e.g. sizing of the flow capacity of the BDV and/or downstream restriction orifice (Haque et al., 1990; Richardson and Saville, 1992; Haque et al., 1992; Biswas and Fischer, 2017; Leporini et al., 2018). The initial rate is used as input to a steady-state flare network simulation. Even individual relief loads from various relief scenarios are analyzed using dynamic simulations (Singh et al., 2007; Firth, 2016; Bjerre et al., 2017; Andreasen et al., 2018). On the other hand, the analysis of the flare system as a whole is typically not subjected to dynamic analysis (Chen et al., 1992).

Andreasen (2014) modeled a sub-part of a flare system on an existing offshore oil and gas production facility. By comparing the system load from steady-state and dynamic simulations, it was found that taking line packing into account via dynamic simulation, the simulated flare tip mass flow rate was $12 \%$ lower than the corresponding steady-state simulation.

Wasnik et al. (2018) studied the depressurization of 14 blowdown segments into an offshore complex flare system. The initial flow from the BDV segments was 545 MMSCFD. The result of a dynamic simulation was that the maximum rate into the flare KO drum was 532 MMSCFD and the maximum load at the flare tip (located $1.8 \mathrm{~km}$ away and connected to the process facility via a 42 " pipeline) was reduced to 447 MMSCFD (18\% reduction from initial BDV rate). In the same study, an extension of an existing facility was also investigated. Dynamic simulations showed that the maximum backpressure calculated during a full plant depressurization was reduced by approx. $17 \%$ compared to steady-state simulation results.

Jo et al. (2020) studied a separator blocked-outlet scenario with multiple PSVs discharging into the flare system of an offshore process facility using dynamic simulations. They found that substantial line sizing optimization could be obtained for most lines compared to a traditional steady-state approach, thereby reducing CAPEX. However, it was also discovered that a few lines had to be increased in size when analyzed in dynamics due to high 
Mach numbers.

Although the literature on dynamic flare system modeling for full plant emergency depressurization is sparse, there are clear indications that existing flare systems designed using a steady-state approach have additional ullage which can be revealed by dynamic simulations. This is especially useful when considering brownfield modifications to existing processing facilities adding equipment that needs to be accommodated within an existing flare system when depressurized. Following a steady-state approach, adding additional flare system load will probably result in bottlenecks in the flare system requiring expensive upgrades. On the other hand, a dynamic modeling approach may elucidate hidden debottlenecking potential by an inherent over-capacity of the original flare system, thereby avoiding expensive flare system upgrades. Dynamic modeling analysis have to be done case by case, since flare systems on different facilities are unique

In this paper, the hidden debottlenecking potential in flare systems on offshore processing facilities is studied using dynamic simulations of the emergency depressurization event.

Three facilities in different sizes in terms of flare system design load and number of segments being depressurized are studied in an attempt to quantify expected built-in ullage. To the authours knowledge, this is the first study reported, which systematically investigates the potential of applying dynamic simulations for revealing hidden debottlenecking potential in existing flare systems.

\section{Methods}

\subsection{Tools and modeling}

All simulations in the present study are conducted with Aspen HYSYS Dynamics ver. 9 (AspenTech, Bedford, Massachusetts, USA). The process fluids are modeled using the Peng-Robinson equation of state (Peng and Robinson, 1976) and the COSTALD method is applied for liquid density (Hankinson and Thomson, 1979). Heavy hydrocarbon fractions are modeled as hypotheticals/pseudo-components.

The blowdown segment is modeled as a vessel in HYSYS with a volume equivalent to the blowdown segment modeled. Heat transfer is not considered in the present study, which means that the dimensions of the vessels used for modeling the blowdown segments are irrelevant, as long as the volume is matched. The BDV for each blowdown segment is modeled as a control valve, 


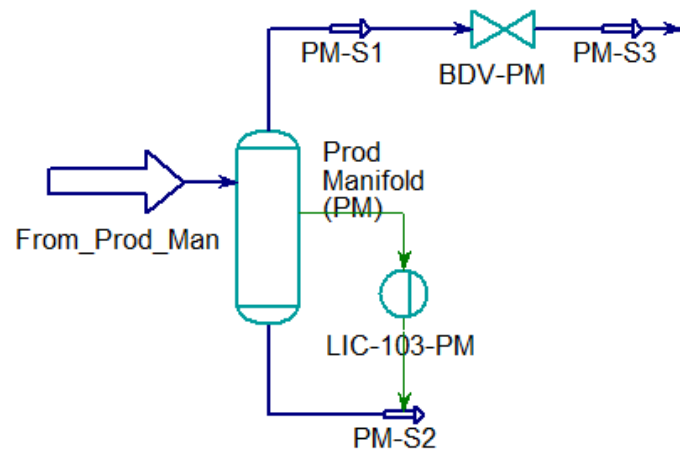

Figure 2: Example of blowdown segment modeling in HYSYS.

with a $\mathrm{C}_{\mathrm{V}}$ calibrated to the initial flow rate through the restriction orifice downstream the BDV. The $\mathrm{C}_{\mathrm{V}}$ is determined by the ANSI/ISA method (ISA, 1995; Borden, 1998) using a semi-ideal $C_{p} / C_{v}$. The modeling of the blowdown segments as a vessel and downstream BDV including restriction orifice (valve and orifice modeled as a control valve) is illustrated in Figure 2. The fluid composition for each blowdown segment is sourced from a corresponding steady-state process simulation of the plant. The initial conditions are set according to the plant's flare, blowdown and relief report. For blowdown segments which extends over pressure change e.g. an entire compressor loop, the initial pressure before start of depressurization is found from a settle-out analysis (Andreasen et al., 2015).

Although the blowdown segments may contain liquids the relief through the BDV is in the vapor state upstream the BDV. Downstream the BDV, smaller amounts of condensation may occur due to Joule-Thomson cooling over the valve.

The flare network is modeled using details from existing Flare System Analyser (FSA) (AspenTech, Bedford, Massachusetts, USA), which includes piping information about length an internal diameter. This information is sourced and used for specifying equivalent HYSYS pipe segments. Fittings data from the equivalent FSA model is included in the HYSYS pipe segments except for swages. Based on the data sourced from FSA, the dynamic model in HYSYS is benchmarked against the steady-state model by running it to a steady-state using the depressurization flow rates from the FSA model as boundary conditions. In the result section of this study the comparison between dynamic simulation results and steady state will be based on the 


\begin{tabular}{lccc}
\hline Facility & \multicolumn{2}{c}{ Design load } & No. BDVs \\
(MMCFD) & $(\mathrm{kg} / \mathrm{h})$ & $(\#)$ \\
\hline A & 73 & 88,000 & 13 \\
B & 341 & 350,000 & 24 \\
C & 714 & 684,000 & 43 \\
\hline
\end{tabular}

Table 2: Summary of facilities flare systems investigated with dynamic simulations.

same dynamic model.

The pipe segment in HYSYS has some shortcomings in its modeling rigor e.g., acceleration pressure drop is not included for pure gas flow, which uses Darcy-Weisbach for pressure drop calculation. Darcy-Weisbach is better suited for incompreesible flow with constant density. For compressible flow with varying density it is notoriously inaccurate. Still, we will use it for simplicity. Each of the tail pipes, sub-headers, and headers modelled are broken down into a vast number of individual segments, providing a discretization and updating mechanism of the fluid density. This will to a large extent mitigate the modeling deficiencies. Compared to more rigorous compressible flow modeling, it is the authors experience that this may lead to a slight underestimation of backpressure with a resulting underestimation of line-packing effect. Hence, the results derived in the present study can be considered conservative. The building of large networks with more rigorous tools, such as e.g. Aspen Hydraulics (AspenTech, Bedford, Massachusetts, USA), is very tedious.

Elevations of tail-pipes, sub-headers and headers are ignored, which is considered to have neglible influence ion the results. Only the contribution to static pressure drop from the elevation of the flare tip is included in the model. The flare tip is modeled as a control valve with a $\mathrm{C}_{\mathrm{V}}$ calibrated to the actual pressure drop at the design rate from vendor data.

\subsection{System description}

Three different flare systems on different offshore facilities are analyzed in the present study. A summary of key data describing the three systems is provided in Table 2 . The three systems investigated span a wide range in flare system size, both in terms of number of process segments disposing into the flare network, in terms of peak design rate and the flare network pipe 
dimensions and total hold-up volume. All three systems are dimensioned for full plant depressurization/emergency depressurization as the governing relief scenario. All BDV's are actuated at once, i.e. no delays or staggered blowdown is applied. No relief from PSVs are included to occur concurrently with the plant depressurization.

\subsection{Facility $A$}

The first facility is an integrated platform designed for light crude with associated gas, which has separation of oil, gas and water in a two-stage separation train with final polishing of crude export in an electrostatic coalescer (final dewatering and desalting). A compression system boosts the gas pressure from the separators for wet gas export/reinjection and gas lift.

The system comprises a combined HP and LP flare system. The governing gas rate design capacity of the flare system is emergency depressurization. The main flare header is 16 " and is routed to the Flare KO Drum. The size of the header is increased to 18" just upstream of the KO drum. A 14" flare line is routed from the $\mathrm{KO}$ drum (ID $3 \mathrm{~m}$ by T/T $10 \mathrm{~m}$ ) to the flare tip. The flare system has 13 BDVs discharging into the flare system upon depressurization. The flare system as modeled in the process simulator is visualized in Figure 3. The details for the blowdown segments are summarised in Table 3.

\begin{tabular}{cccccccc}
\hline & Pressure & Temperature & Total volume & Liquid Volume & Initial BDV rate & Gas MW \\
BDV No. & $($ bar $)$ & $\left({ }^{\circ} \mathrm{C}\right)$ & $\left(\mathrm{m}^{3}\right)$ & $\left(\mathrm{m}^{3}\right)$ & $(\mathrm{kg} / \mathrm{h})$ & $($ MMSCFD $)$ & $(\mathrm{kg} / \mathrm{kmole})$ \\
\hline 1 & 36.0 & 93.4 & 101.0 & 70.9 & 26,836 & 22.36 & 23.8 \\
2 & 63.4 & 64.8 & 1.8 & 0.7 & 4,610 & 3.97 & 21.8 \\
3 & 68.6 & 64.8 & 4.6 & 1.8 & 9,140 & 7.87 & 21.8 \\
4 & 2.5 & 80.0 & 113.1 & 67.7 & 11,656 & 5.85 & 40.0 \\
5 & 36.0 & 93.4 & 49.8 & 31.3 & 19,578 & 16.48 & 23.8 \\
6 & 180.0 & 111.9 & 0.4 & 0.0 & 1,391 & 1.14 & 24.5 \\
7 & 4.9 & 38.0 & 15.2 & 1.9 & 3,996 & 1.74 & 38.0 \\
8 & 13.2 & 45.0 & 5.6 & 0.9 & 3,319 & 0.96 & 34.0 \\
9 & 34.0 & 93.4 & 3.6 & 0.2 & 1,561 & 1.35 & 24.0 \\
10 & 125.0 & 115.0 & 1.9 & 0.0 & 3,044 & 2.49 & 24.5 \\
11 & 40.6 & 40.0 & 1.3 & 0.0 & 6,544 & 5.16 & 24.3 \\
12 & 130.9 & 75.0 & 3.7 & 1.1 & 10,209 & 8.34 & 24.5 \\
13 & 31 & 93.4 & 3.6 & 0.2 & 500 & 0.43 & 24.0 \\
\hline
\end{tabular}

Table 3: Summary of specifications for blowdown segments of Facility A. The conditions are for the initial system state prior to depressurization. 


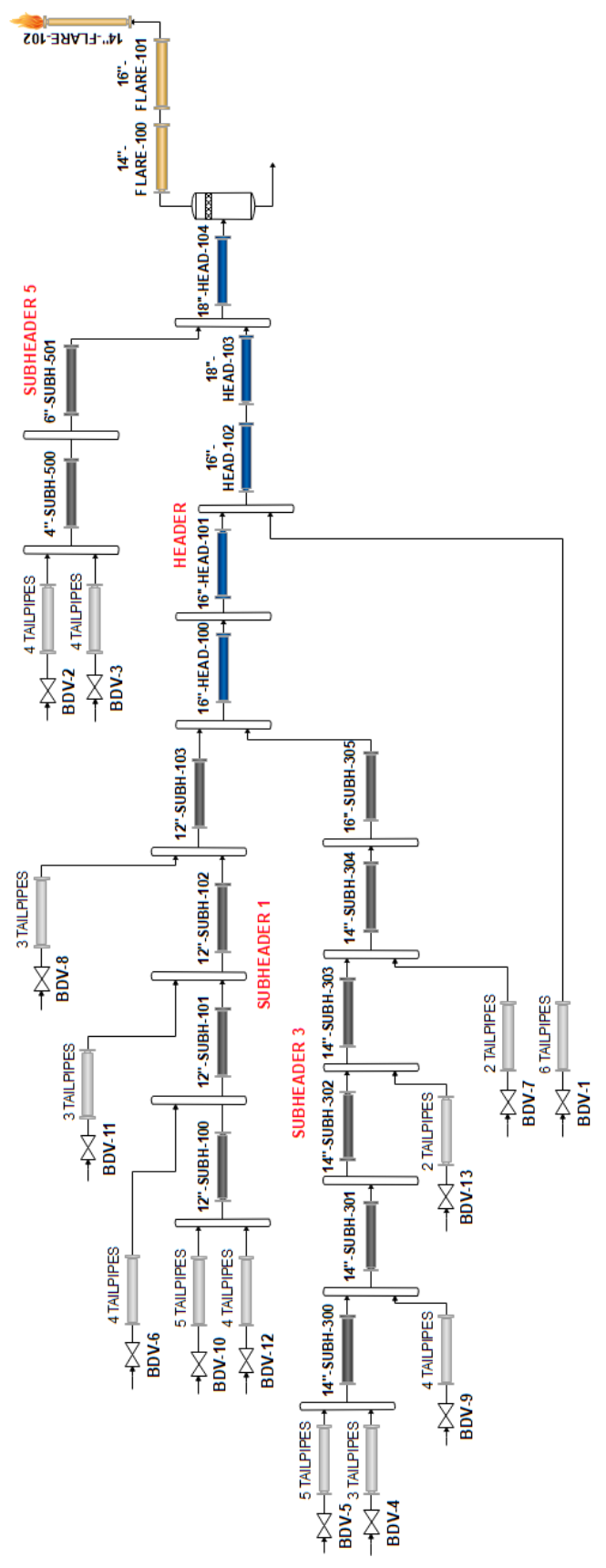

Figure 3: Flare system model for facility A. Dead ends from PSVs and PCVs not disposing into the flare system during emergency depressurization have not been included. 


\subsection{Facility $B$}

Facility $\mathrm{B}$ is a gas-condensate integrated processing platform, with twostage condensate knock-out and booster compression of flash-gas from the $2^{\text {nd }}$ stage separator. Before export, the gas is dehydrated and dew point controlled (hydrocarbons).

The platform has separate LP and HP flare systems, but only the HP flare is modeled in the present study. The main flare header is 20 " and is routed to the flare KO drum. A 20" flare line is routed from the KO drum (ID $3 \mathrm{~m}$ by $\mathrm{T} / \mathrm{T} 7.2 \mathrm{~m}$ ) to the flare stack/tip. The flare system has 24 BDVs disposing into the flare system upon depressurization. The flare system as modeled in the process simulator is visualized in Figure 4. The details for the blowdown segments are summarised in Table 4.

\begin{tabular}{cccccccc}
\hline & Pressure & Temperature & Total volume & Liquid Volume & Initial BDV rate & Gas MW \\
BDV No. & $($ bar $)$ & $\left({ }^{\circ} \mathrm{C}\right)$ & $\left(\mathrm{m}^{3}\right)$ & $\left(\mathrm{m}^{3}\right)$ & $(\mathrm{kg} / \mathrm{h})$ & $($ MMSCFD $)$ & $(\mathrm{kg} / \mathrm{kmole})$ \\
\hline 1 & 87.9 & 68.2 & 0.3 & 0.1 & 627 & 0.6 & 20.3 \\
2 & 55.0 & 88.1 & 0.3 & 0.1 & 375 & 0.4 & 20.6 \\
3 & 41.5 & 47.7 & 0.6 & 0.1 & 524 & 0.5 & 20.4 \\
4 & 41.2 & 69.0 & 0.5 & 0.1 & 537 & 0.5 & 20.7 \\
5 & 42.4 & 85.7 & 0.6 & 0.0 & 528 & 0.5 & 20.8 \\
6 & 41.6 & 72.8 & 0.9 & 0.0 & 531 & 0.5 & 20.7 \\
7 & 40.9 & 67.7 & 30.9 & 1.4 & 15,943 & 15.5 & 21.7 \\
8 & 40.0 & 58.1 & 3.7 & 2.5 & 1.797 & 1.8 & 20.4 \\
9 & 89.9 & 84.8 & 22.3 & 3.6 & 26,717 & 25.2 & 21.2 \\
10 & 24.0 & 30.7 & 105.7 & 58.5 & 23,721 & 22.5 & 21.0 \\
11 & 56.2 & 35.0 & 7.4 & 0.0 & 4,674 & 4.7 & 19.7 \\
12 & 22.3 & 30.6 & 7.9 & 7.4 & 20,035 & 18.8 & 21.8 \\
13 & 56.4 & 35.0 & 8.5 & 0.0 & 9,609 & 9.8 & 19.7 \\
14 & 76.5 & 39.5 & 82.3 & 34.9 & 99,998 & 95.9 & 20.2 \\
15 & 40.7 & 52.1 & 6.7 & 0.1 & 2,207 & 2.1 & 21.0 \\
16 & 75.0 & 19.0 & 41.3 & 7.3 & 41,878 & 40.4 & 20.5 \\
17 & 56.6 & -9.1 & 59.6 & 17.7 & 51,306 & 54.1 & 20.0 \\
18 & 65.4 & 39.2 & 5.3 & 0.0 & 3,872 & 3.9 & 19.7 \\
19 & 14.0 & 45.4 & 2.4 & 0.0 & 235 & 0.2 & 19.7 \\
20 & 95.2 & 49.5 & 10.9 & 3.4 & 13,520 & 13.2 & 20.5 \\
21 & 101.4 & 75.7 & 0.4 & 0.1 & 1,642 & 1.6 & 21.1 \\
22 & 58.7 & 33.8 & 1.1 & 0.0 & 1,039 & 1.0 & 20.9 \\
23 & 67.0 & 45.4 & 3.9 & 0.0 & 8,617 & 8.3 & 20.9 \\
24 & 25.9 & 30.7 & 1.5 & 1.5 & 19,901 & 18.9 & 21.3 \\
\hline
\end{tabular}

Table 4: Summary of specifications for blowdown segments of Facility B. The conditions are for the initial system state prior to depressurization. 


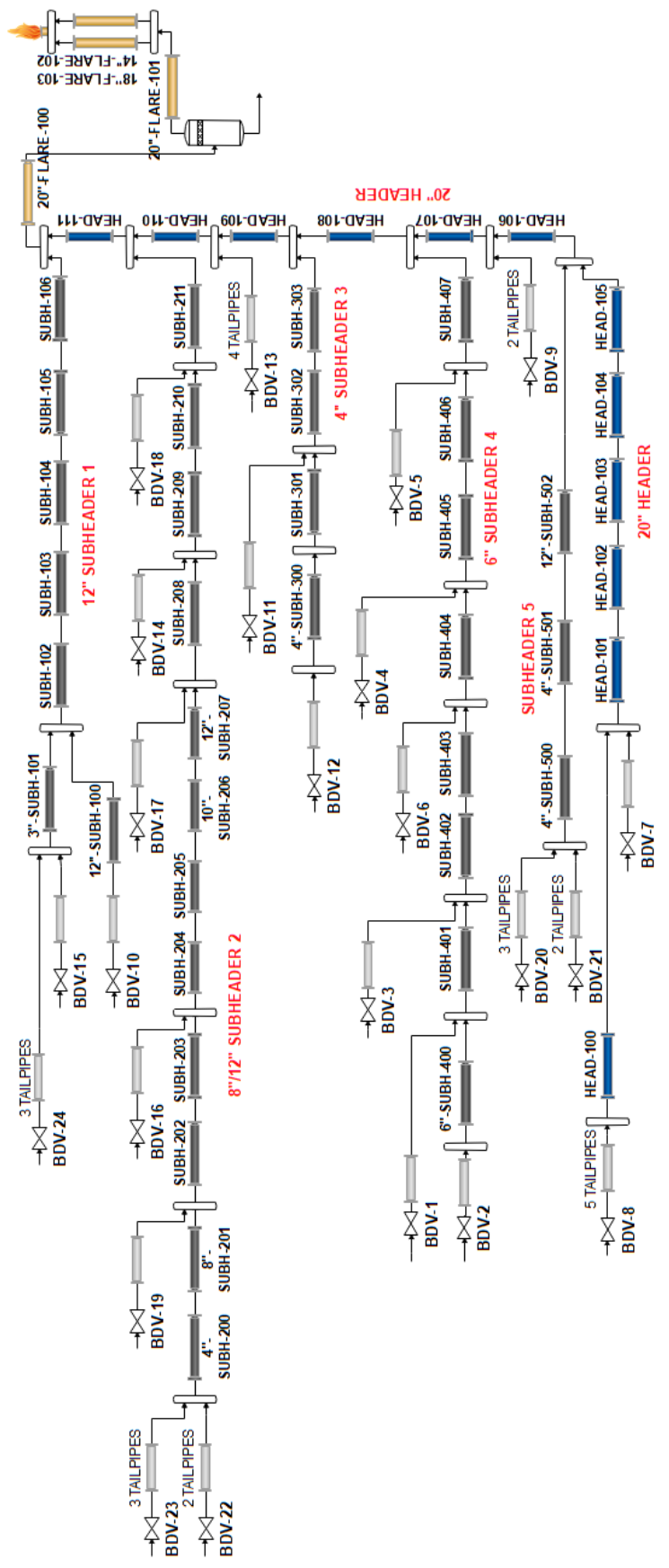

Figure 4: Flare system model for facility B. Dead ends from PSVs and PCVs not disposing into the flare system during emergency depressurization have not been included. 


\subsection{Facility $C$}

The last facility modeled is a central processing facility handling production from a number of bridge-connected platforms including tie-backs from remote facilities. Mainly gas condensate is handled and oil/water/gas separation is performed including gas compression dehydration and hydrocarbon dew-pointing. The CPF exports gas to shore as well as it provides gas lift to wells requiring artificial lift.

The flare system includes both an LP and HP flare system, but only the HP flare system is modeled. The HP flare system has separate 18" main headers for cold and warm (wet) flare terminating at the flare $\mathrm{KO}$ drum (ID $3.55 \mathrm{~m} \times \mathrm{T} / \mathrm{T} 10.6 \mathrm{~m}$ ). A 24" flare line is routed from the $\mathrm{KO}$ drum to the flare stack/tip. The flare system has 43 BDVs disposing into the flare system upon depressurization. The flare system as modeled in the process simulator is visualized in Figure 5. The details for the blowdown segments are summarised in Table 5.

\section{Results and Discussion}

\subsection{Facility $A$}

For facility A, the emergency depressurization process is simulated using the dynamic process model depicted in Figure 3. Two simulations are conducted; The first uses a fixed pressure boundary upstream all BDVs at the value of the initial pressure prior to blowdown and the dynamic simulation is run until steady-state is reached. This relates to the approach applied when using a steady-state network solver, where the peak flow is used. The second applies a zero flow boundary at the inlet of the blowdown segments i.e. the pressure decreases with time in the blowdown segments concurrently with the mass flow out of the blowdown valve/orifice. This simulates the real dynamic behavior of the system with mass flow from blowdown segment decreasing with time as the pressure upstream decreases.

In Figure 6, the backpressure in various places in the flare system, calculated using the steady-state approach and the full dynamic approach, are depicted. As seen from the results, the peak backpressure with the dynamic approach is lower than the corresponding steady-state value. This behavior is similar to the one observed by Wasnik et al. (2018).

The mass flow reaching the flare tip is also compared for the steady-state and dynamic simulations. This is shown in Figure 7. Included is also a simulation run with a model with increased complexity, referred to as a dead 


\begin{tabular}{|c|c|c|c|c|c|c|}
\hline BDV No. & $\begin{array}{l}\text { Pressure } \\
\text { (bar) }\end{array}$ & $\begin{array}{c}\text { Temperature } \\
\left({ }^{\circ} \mathrm{C}\right)\end{array}$ & $\begin{array}{l}\text { Total volume } \\
\qquad\left(\mathrm{m}^{3}\right)\end{array}$ & $\begin{array}{l}\text { Liquid Volume } \\
\qquad\left(\mathrm{m}^{3}\right)\end{array}$ & $\begin{array}{l}\text { Initial BDV rate } \\
\qquad(\mathrm{kg} / \mathrm{h})\end{array}$ & $\begin{array}{l}\text { Gas MW } \\
\mathrm{kg} / \mathrm{kmole}\end{array}$ \\
\hline 1 & 50.0 & 31.0 & 41.0 & 13.3 & 16,260 & 18.9 \\
\hline 2 & 23.8 & 48.2 & 56.6 & 3.6 & 10,230 & 19.2 \\
\hline 3 & 55.0 & 55.0 & 47.2 & 2.6 & 18,507 & 19.3 \\
\hline 4 & 72.0 & 30.0 & 67.2 & 9.1 & 41,714 & 19.3 \\
\hline 5 & 62.6 & 6.5 & 17.5 & 1.7 & 13,375 & 18.9 \\
\hline 6 & 62.6 & 6.5 & 17.5 & 1.7 & 13,375 & 18.9 \\
\hline 7 & 137.6 & 49.0 & 8.5 & 0.0 & 14,075 & 19.2 \\
\hline 8 & 114.6 & 48.8 & 15.8 & 0.0 & 19,137 & 18.5 \\
\hline 9 & 50.0 & 15.9 & 4.1 & 1.9 & 13,798 & 20.0 \\
\hline 10 & 138.0 & 45.0 & 16.7 & 0.0 & 27,107 & 18.5 \\
\hline 11 & 15.0 & 55.0 & 155.5 & 155.5 & 15,329 & 23.1 \\
\hline 12 & 9.7 & 75.1 & 9.0 & 0.5 & 0 & 34.5 \\
\hline 13 & 9.7 & 75.1 & 9.0 & 0.5 & 0 & 34.5 \\
\hline 14 & 72.0 & 26.0 & 9.5 & 0.0 & 6,893 & 19.2 \\
\hline 15 & 50.0 & 28.2 & 8.6 & 0.1 & 4,087 & 19.3 \\
\hline 16 & 63.0 & 24.2 & 20.8 & 0.0 & 11,488 & 18.5 \\
\hline 17 & 72.0 & 25.0 & 67.5 & 6.1 & 58,678 & 19.7 \\
\hline 18 & 50.0 & 31.7 & 62.3 & 37.8 & 101,354 & 18.6 \\
\hline 19 & 50.0 & 31.7 & 14.3 & 9.3 & 22,285 & 18.6 \\
\hline 20 & 50.0 & 31.7 & 5.4 & 5.4 & 104,121 & 26.4 \\
\hline 21 & 50.0 & 31.7 & 32.4 & 32.4 & 8,466 & 26.4 \\
\hline 22 & 50.0 & 28.2 & 74.2 & 0.7 & 29,908 & 18.8 \\
\hline 23 & 50.0 & 28.2 & 3.7 & 0.0 & 1,476 & 18.8 \\
\hline 24 & 50.0 & 28.2 & 3.7 & 0.0 & 1,373 & 18.8 \\
\hline 25 & 50.0 & 28.2 & 10.7 & 0.1 & 4,325 & 18.8 \\
\hline 26 & 50.0 & 36.1 & 51.6 & 1.3 & 21,989 & 18.6 \\
\hline 27 & 50.0 & 36.1 & 4.4 & 0.1 & 2,008 & 18.6 \\
\hline 28 & 138.0 & 44.7 & 28.9 & 0.0 & 47,256 & 18.5 \\
\hline 29 & 138.0 & 44.7 & 17.3 & 0.0 & 28,254 & 18.5 \\
\hline 30 & 72.0 & -7.8 & 0.2 & 0.2 & 3,914 & 20.0 \\
\hline 31 & 72.0 & -7.8 & 1.3 & 1.3 & 12,185 & 18.5 \\
\hline 32 & 72.0 & 1.4 & 61.2 & 6.1 & 59,171 & 18.4 \\
\hline 33 & 125.0 & 1.4 & 1.8 & 0.0 & 4,096 & 19.1 \\
\hline 34 & 80.0 & 1.4 & 0.9 & 0.0 & 954 & 18.5 \\
\hline 35 & 170.0 & 28.5 & 9.1 & 0.0 & 24,445 & 19.2 \\
\hline 36 & 192.0 & 36.9 & 0.6 & 0.0 & 1,793 & 19.2 \\
\hline 37 & 138.0 & 44.7 & 26.5 & 0.0 & 48,273 & 18.5 \\
\hline 38 & 138.0 & 44.7 & 13.3 & 0.0 & 24,304 & 18.5 \\
\hline 39 & 138.0 & 44.7 & 35.6 & 0.0 & 70,405 & 18.5 \\
\hline 40 & 192.0 & 36.9 & 9.5 & 0.0 & 29,933 & 19.2 \\
\hline 41 & 192.0 & 36.9 & 0.7 & 0.0 & 2,121 & 19.2 \\
\hline 42 & 192.0 & 36.9 & 0.7 & 0.0 & 2,274 & 19.2 \\
\hline 43 & 97.1 & 52.6 & 7.9 & 0.0 & 7,956 & 18.5 \\
\hline
\end{tabular}

Table 5: Summary of specifications for blowdown segments of Facility C. 


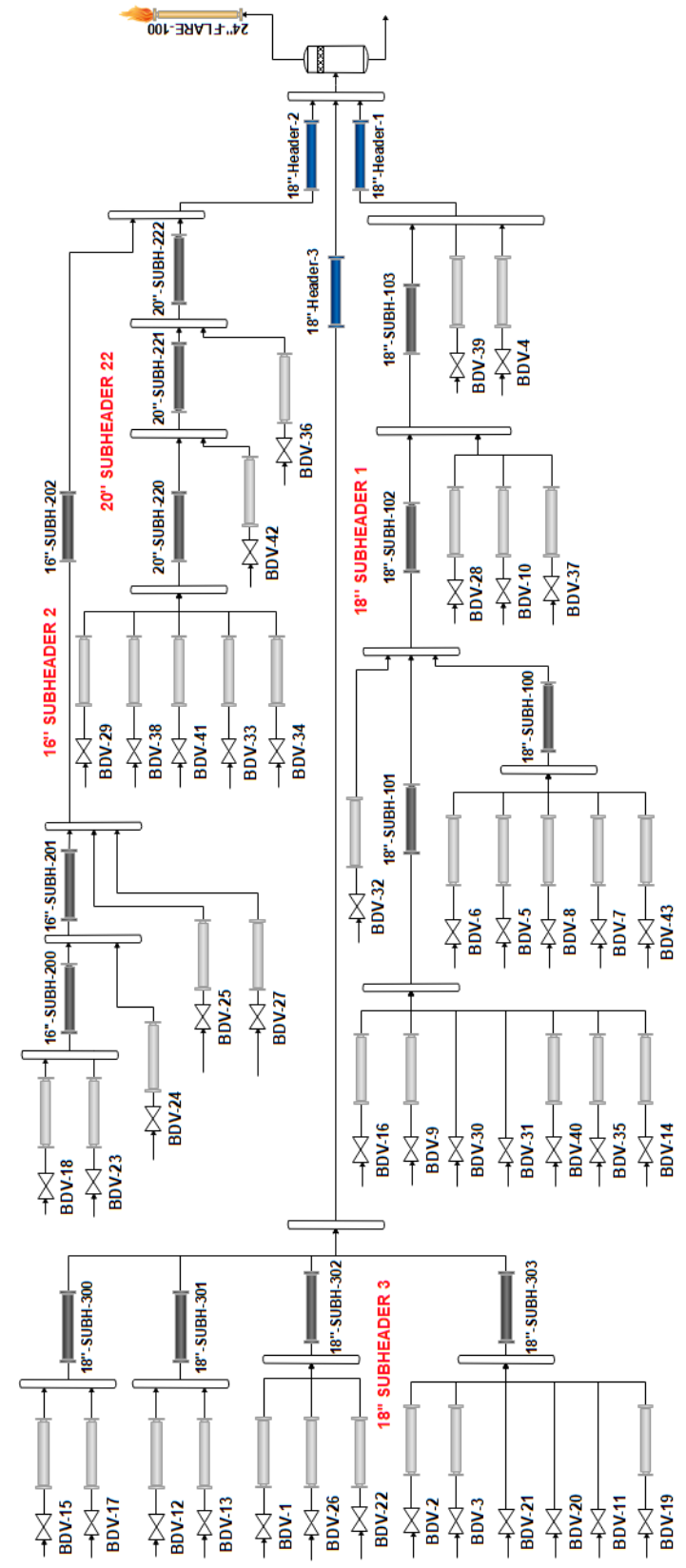

Figure 5: Flare system model for facility C. Dead ends from PSVs and PCVs not disposing into the flare system during emergency depressurization have not been included. 


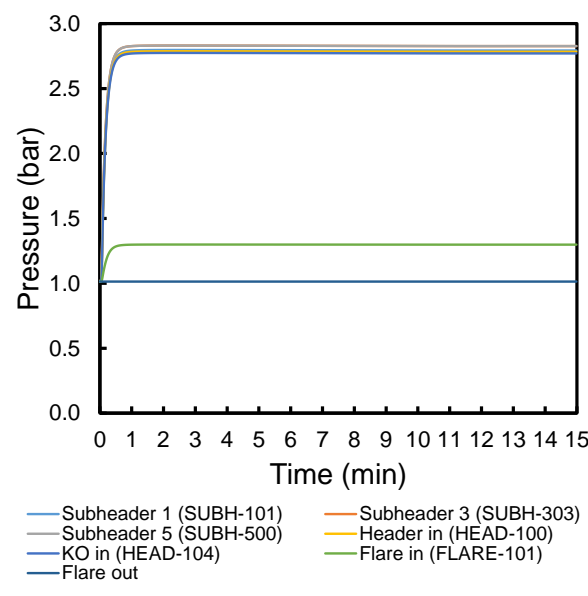

(A)

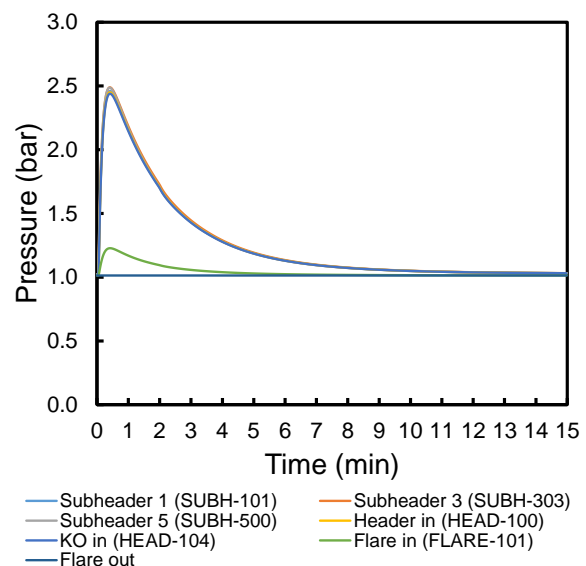

(B)

Figure 6: Comparison between calculated backpressure in selected flare lines, flare KO drum for (A) steady-state and (B) dynamic simulations for facility A.

ends model In this more complex model, all tail pipes and sub-headers from non-flow sources such as PSVs and PCVs which normally do not dispose into the flare system during emergency depressurization have been included. This can be compared back-to-back in the Suplpemetary Material.

As seen from Figure 7, the mass flow rate in the dynamic simulations, both the with and without dead ends increases rapidly to a maximum value at a time between 0.5-1 min. after start of the depressurization. The maximum mass flow rate is at a lower value than the steady-state value due to linepacking in the flare system in agreement with previous findings (Andreasen, 2014; Wasnik et al., 2018). It is also noted that the peak mass flow is reduced by including the dead ends in the dynamic simulation model. The dead ends contribute with increased hold-up volume and hence a bigger line-packing potential. The reduction in peak flare rate is $11,370 \mathrm{~kg} / \mathrm{h}$ and $13,994 \mathrm{~kg} / \mathrm{h}$ for the dynamic model without and with dead ends, respectively. In relative numbers, the reduction is $13 \%$ and $16 \%$.

\subsection{Facility $B$}

For facility B, the emergency depressurization process is simulated using the dynamic process model depicted in Figure 4 in ??. Again, two simulations are conducted; a dynamic simulation run to a steady-state using the initial peak flow from blowdown segments and the full dynamic simulation. 


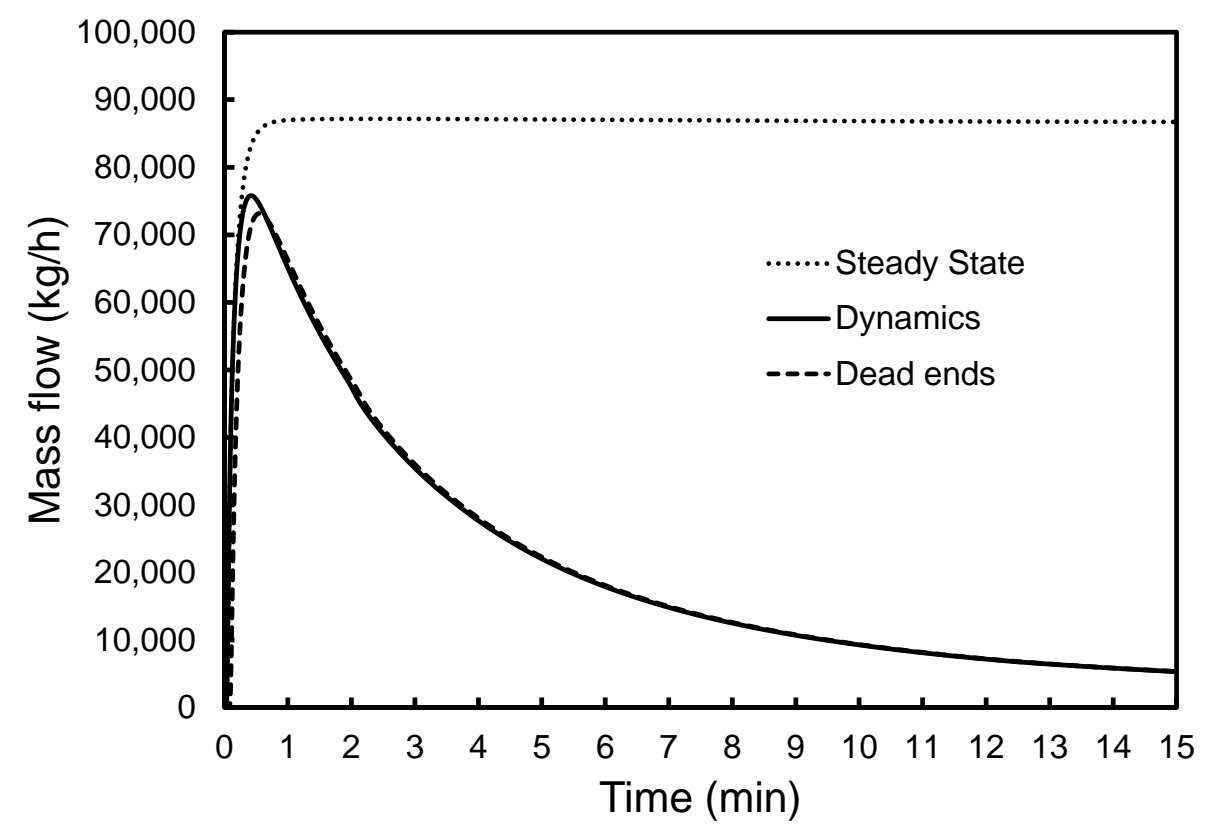

(A)

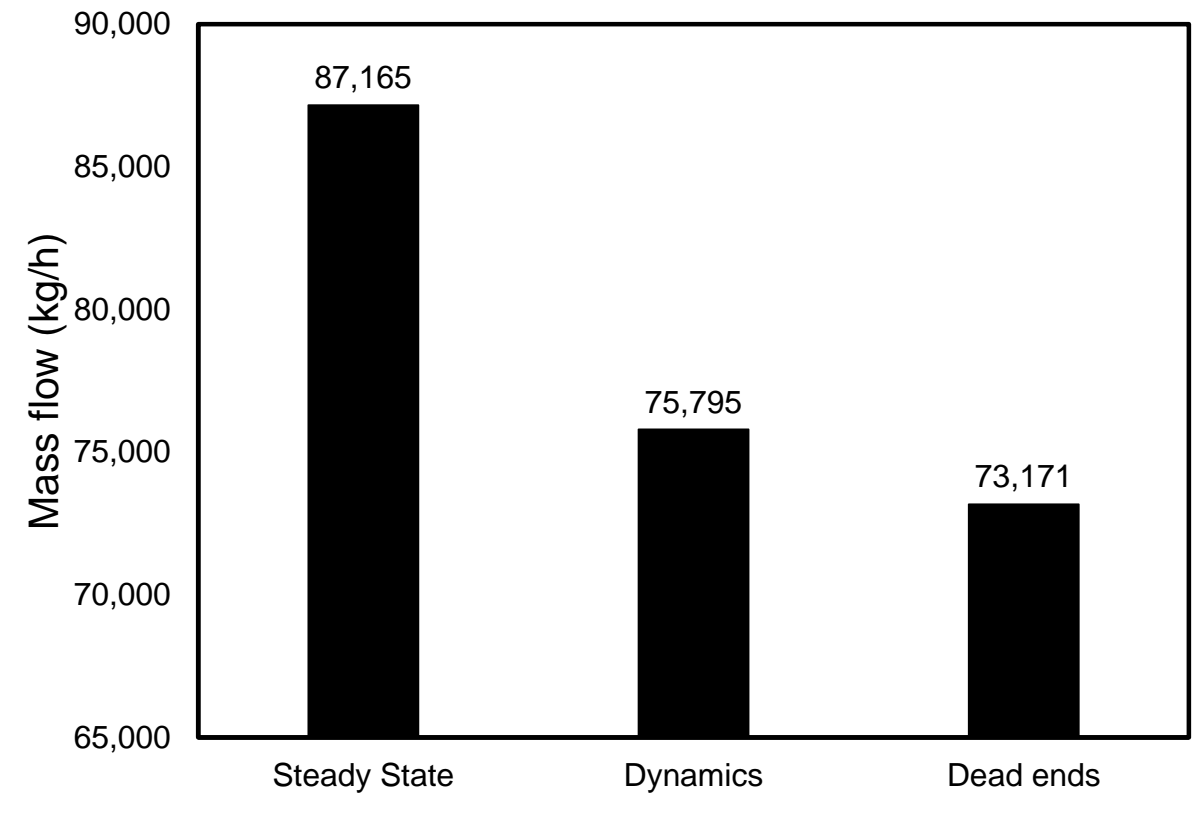

(B)

Figure 7: Comparison between calculated flare-tip mass flow for facility A for steady-state, dynamic simulations without dead ends, and dynamic simulations including dead ends. 


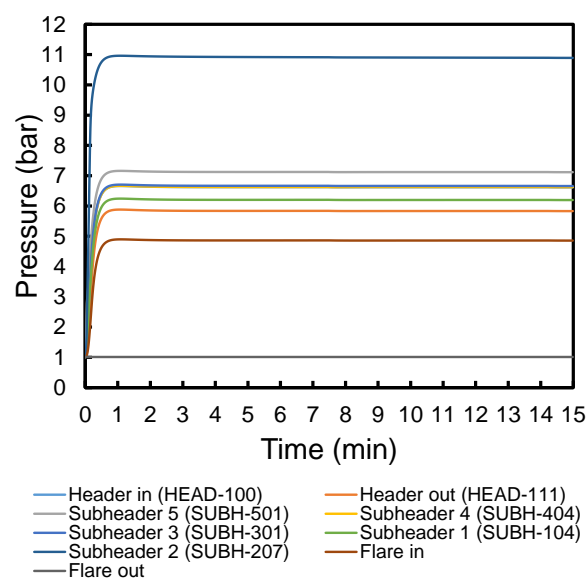

(A)

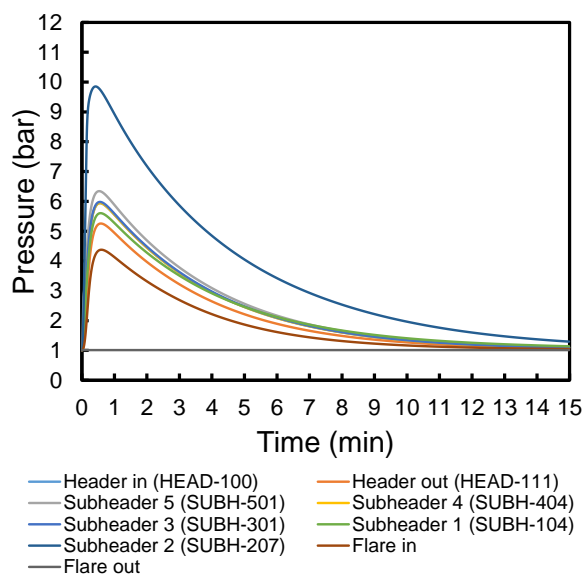

(B)

Figure 8: Comparison between calculated backpressure in selected flare lines, flare KO drum for (A) steady-state and (B) dynamic simulations for facility B.

In Figure 8 the backpressures in various places in the flare system calculated using the steady-state and the full dynamic approach are depicted. As seen from the results, the peak backpressure with the dynamic approach is lower than the corresponding steady-state value as also demonstrated for the facility A model.

The mass flow reaching the flare tip is also compared for the steady-state and dynamic simulations. This is shown in Figure 9. The results also include a more complex model which includes all dead ends as described for facility A. The flowsheets with and without dead ends for facilty B can be compared back-to-back in the Supplementary Material.

As seen from Figure 9, the mass flow in the dynamic simulations both the one with and the one without dead ends increase rapidly to a maximum value at a time between 0.5-1 min. after start of depressurization. The maximum mass rate is at a lower value than the steady-state value as also shown for facility A. Again, it is noted that the peak mass flow is reduced by including the dead ends in the dynamic simulation model. The reduction in peak flare rate is $41,670 \mathrm{~kg} / \mathrm{h}$ and $44,329 \mathrm{~kg} / \mathrm{h}$ for the dynamic model without and with dead ends, respectively. In relative numbers, the reduction is $13.5 \%$ and $14.4 \%$. Compared to facility $\mathrm{A}$, the reduction in flare rate is higher in absolute numbers for facility $\mathrm{B}$, whereas the relative reduction is comparable. In absolute numbers, the inclusion of dead ends is very similar to Facility A, 


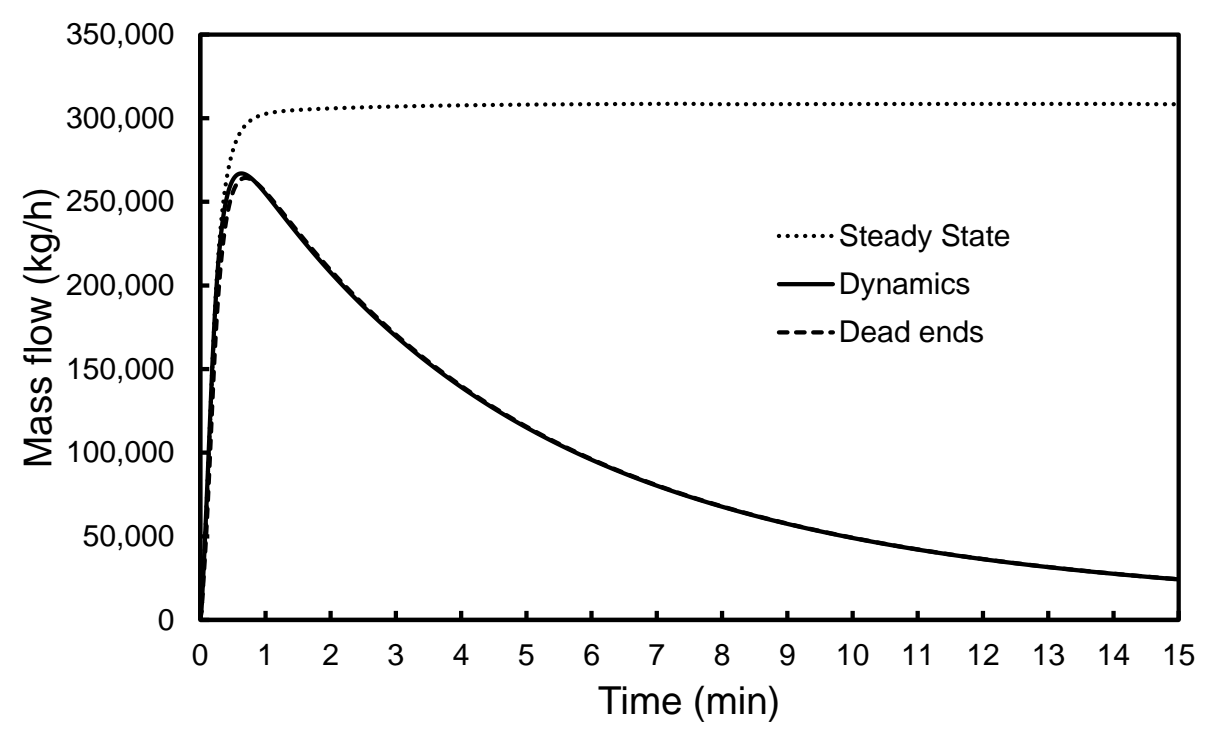

(A)

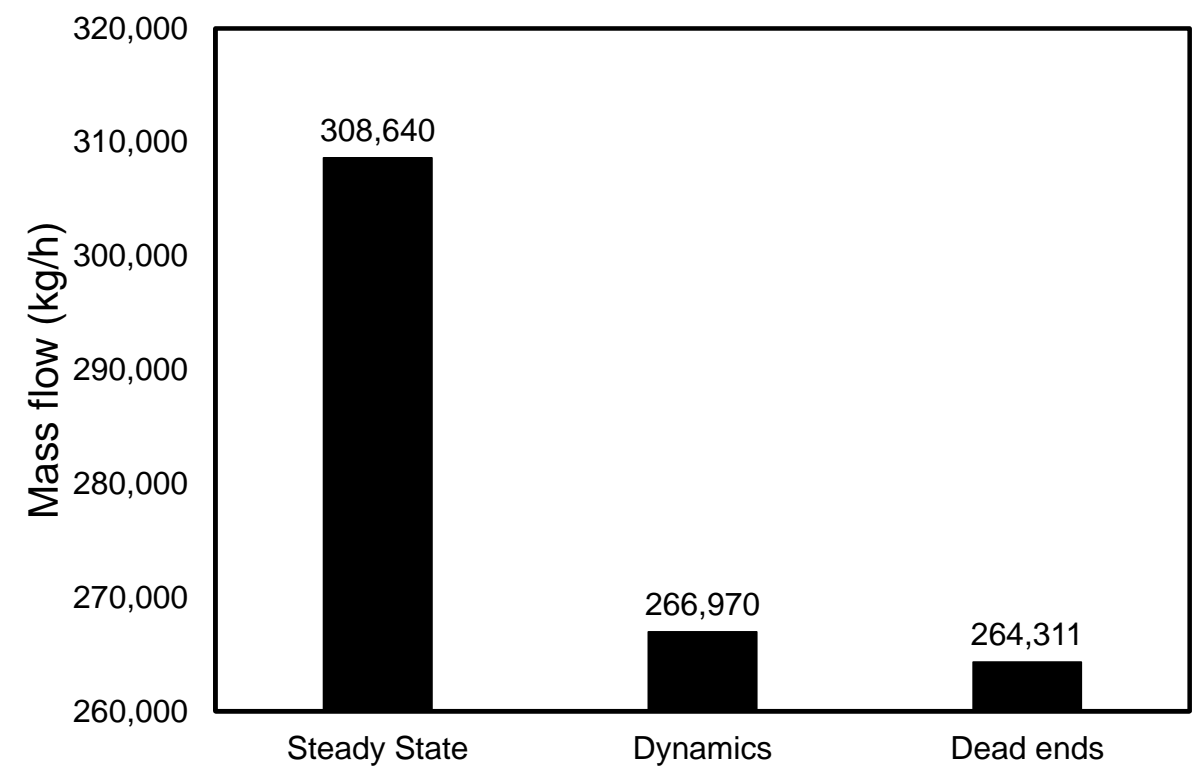

(B)

Figure 9: Comparison between calculated flare-tip mass flow for facility B for steady-state, dynamic simulations without dead ends and dynamic simulations including dead ends. 


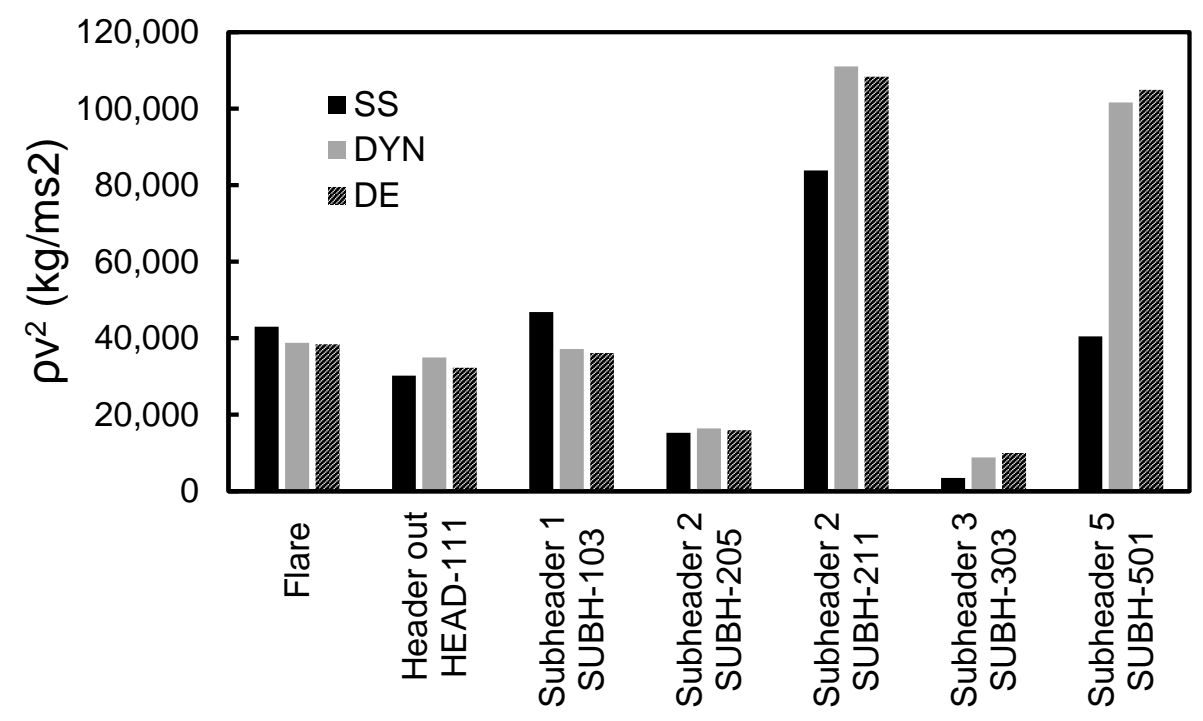

Figure 10: Comparison between calculated peak $\rho \mathrm{v}^{2}$ Facility B for steady-state, dynamic simulations without dead ends, and dynamic simulations including dead ends.

but less significant in relative numbers.

Combined with findings from facility A, the simulation results for facility B suggest that it can be beneficial to build a simulation model including all system volumes. On the other hand, using a less complex model is conservative. Apparently, the larger facility $\mathrm{B}$ shows less reduction in flare rate by including dead ends as facility A. Although, not conclusive, this might suggest that a more accurate and detailed model is more important for a smaller facility.

In order to also assess the consequence of a dynamic simulation analysis of a flare system, on $\rho \mathrm{v}^{2}$, one of the key design parameters, this is compared between the steady-state model and the dynamic models without and with dead ends. Comparison is made between the peak values during dynamic simulations and corresponding steady-state values for the main sub-headers, headers and main line to the flare tip in Figure 10.

As seen from Figure 10, the calculated peak $\rho \mathrm{v}^{2}$ using the dynamic simulations is higher than the corresponding steady-state value for some of the investigated sub-headers and headers e.g. Subheader 5 and Subheader 2 out. This phenomenon may be rationalized in terms of a lower peak backpressure as illustrated in Figure 8 for the dynamic simulations. A lower pressure re- 
sults in lower density and hence larger actual value flows, which translates to higher velocity. Although a lower density counterbalances a higher velocity, the velocity dominates since it is a squared term. Jo et al. (2020) also observed that in some flare lines, the Mach numbers calculated in a dynamic simulation exceeded those from a steady-state simulation. In some locations the $\rho \mathrm{v}^{2}$ for the dynamic model is lower that the steady-state model as shown for the flare.

This is an important takeaway when analyzing dynamic flare models, and while lower mass flow rates and lower backpressure are important for identifying spare capacity in the flare system, it is important also to analyze other key design factors such as $\rho \mathrm{v}^{2}$ and Mach number.

\subsection{Facility $C$}

For facility $\mathrm{C}$, the mass flow reaching the flare tip is compared for the steady-state and dynamic simulations. This is shown in Figure 11. The details available for facility $\mathrm{C}$ have not allowed an analysis of the effect of dead-ends.

As seen from Figure 11, the peak mass flow in the dynamic simulations is at a lower value than the steady-state value as also shown for facility $\mathrm{A}$ and B. The dynamic simulations results in a peak flare rate of $511,989 \mathrm{~kg} / \mathrm{h}$ at the flare tip compared to a steady-state value of $676,473 \mathrm{~kg} / \mathrm{h}$. The reduction in peak flare rate is $164,484 \mathrm{~kg} / \mathrm{h}$ for the dynamic model which corresponds to a reduction of $24.3 \%$. Compared to both facility $\mathrm{A}$ and $\mathrm{B}$, the reduction in flare rate for facility $\mathrm{C}$ is higher in both absolute numbers and in relative numbers. In absolute numbers, the order of reduction in peak flare rate is the following $\mathrm{A}<\mathrm{B}<\mathrm{C}$.

\subsection{Synthesis}

The results from the analysis of all three facilities are summarized in Table 6. The main results are the steady-state design rate and the corresponding peak flare rate at the flare tip as found from a dynamic simulation of the emergency depressurization process. More specifically the difference between the steady-state and dynamic analysis, also termed the hidden potential for debottlenecking is included. Further, included are also details about the flare system in terms of hold-up volumes, flare network length and average flare piping diameter.

It is seen from Table 6, that generally the total system volume of the flare system including both piping and the flare KO drum scales with the 


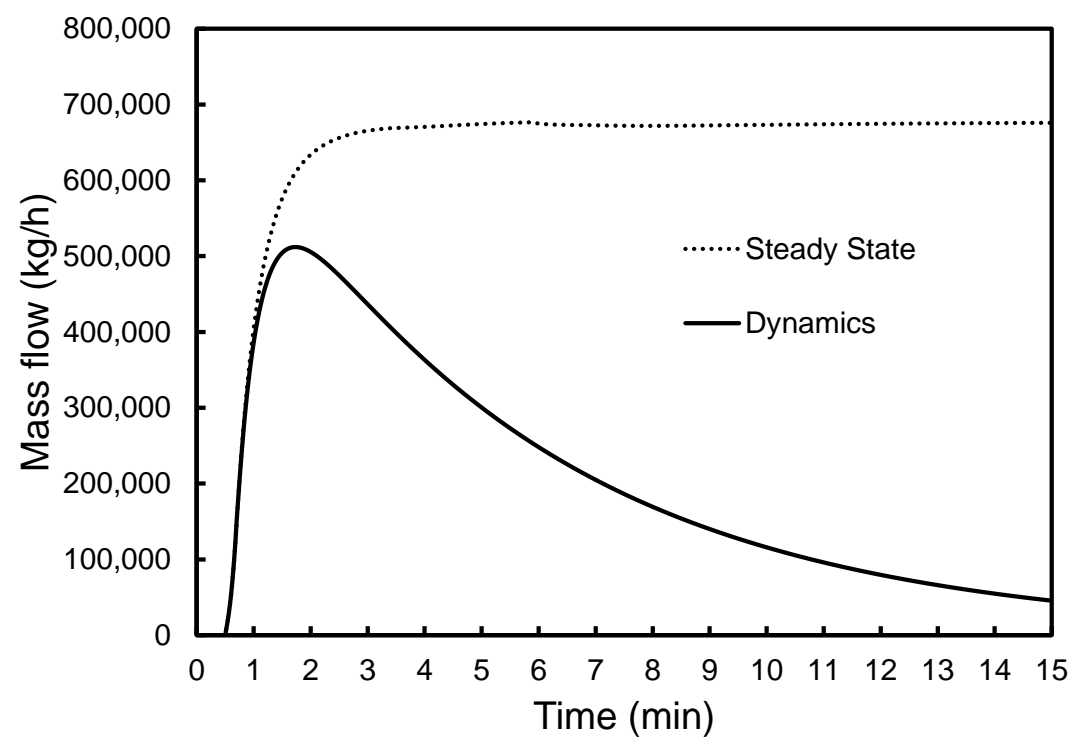

(A)

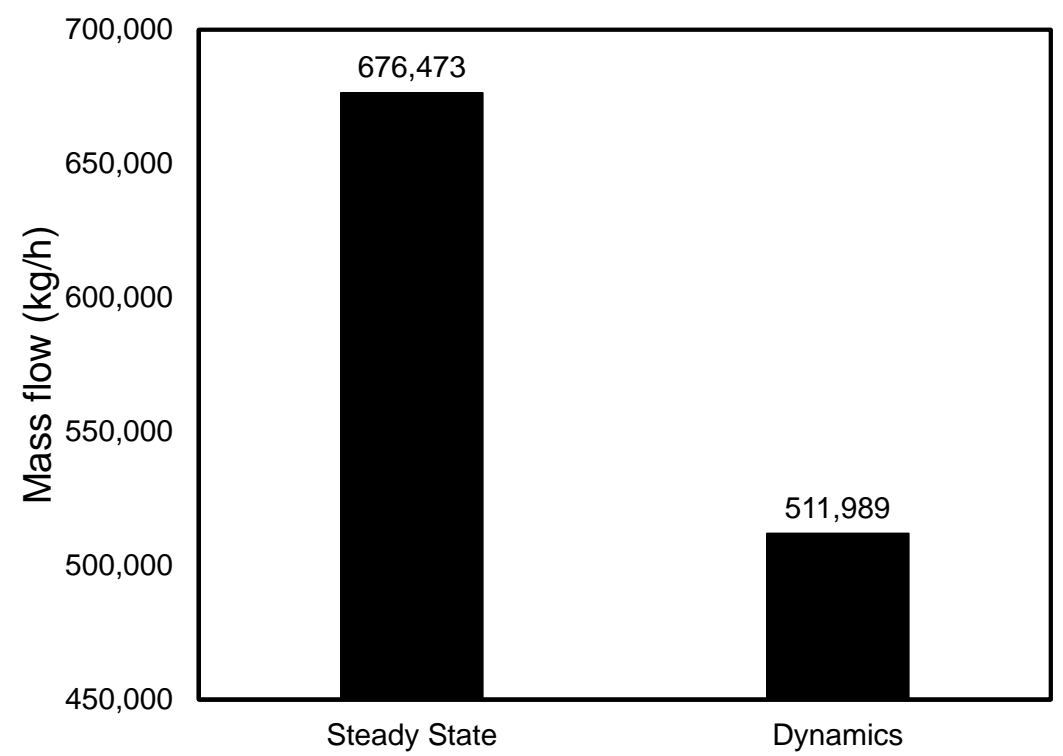

(B)

Figure 11: Comparison between calculated flare-tip mass flow for facility $\mathrm{C}$ for steady-state and dynamic simulations without dead ends. 


\begin{tabular}{|c|c|c|c|c|c|c|c|c|c|c|}
\hline \multirow[b]{2}{*}{ Facility } & \multirow[b]{2}{*}{ Dead end } & \multirow[b]{2}{*}{$\begin{array}{l}\mathrm{L}_{\text {net }} \\
(\mathrm{m})\end{array}$} & \multirow[b]{2}{*}{$\begin{array}{l}V_{\text {pipe }} \\
\left(\mathrm{m}^{3}\right)\end{array}$} & \multirow[b]{2}{*}{$\begin{array}{l}\mathrm{V}_{\mathrm{KO}} \\
\left(\mathrm{m}^{3}\right)\end{array}$} & \multirow[b]{2}{*}{$\begin{array}{l}V_{\text {tot }} \\
\left(\mathrm{m}^{3}\right)\end{array}$} & \multirow[b]{2}{*}{$\begin{array}{l}\mathrm{D}_{\text {mean }} \\
\text { (inch) }\end{array}$} & \multicolumn{2}{|c|}{ Peak flare rate } & \multirow{2}{*}{\multicolumn{2}{|c|}{ Hidden potential }} \\
\hline & & & & & & & $\begin{array}{l}\text { SS } \\
\text { (MMS }\end{array}$ & $\begin{array}{l}\text { Dyn. } \\
\text { FD) }\end{array}$ & & $\begin{array}{l}\text { atial } \\
(\%)\end{array}$ \\
\hline \multirow[t]{2}{*}{$\mathrm{A}$} & no & 288 & 19.2 & 79.4 & 98.6 & 10.5 & 72.8 & 63.2 & 9.5 & 13.0 \\
\hline & yes & 497 & 27.0 & 79.4 & 106.4 & 9.3 & 72.8 & 61.1 & 11.7 & 16.1 \\
\hline \multirow[t]{2}{*}{ B } & no & 1,457 & 126 & 50.5 & 176.6 & 11.7 & 303.1 & 262.2 & 40.9 & 13.5 \\
\hline & yes & 2,034 & 150 & 50.5 & 200.5 & 10.7 & 303.1 & 259.5 & 43.5 & 14.4 \\
\hline $\mathrm{C}$ & no & 2,686 & 359.6 & 103.3 & 462.9 & 15.3 & 733.2 & 555.0 & 178.2 & 24.3 \\
\hline
\end{tabular}

Table 6: Summary of model details and modeling results for all three investigated facilities. Results included for models without and with dead ends included. $\mathrm{L}_{\text {net }}$ : Total length of piping included in the flare network model, $\mathrm{V}_{\text {pipe }}$ : Hold-up volume of modeled piping, $\mathrm{V}_{\mathrm{KO}}$ : Hold-up volume of flare Knock-out drum, $V_{\text {tot }}$ : Total hold-up volume of flare system, $\mathrm{D}_{\text {mean }}$ : Average diameter of flare network piping, found from a weighted average with individual piping diameters weighted by their corresponding pipe length.

steady-state design rate, which is partly due the average piping diameter being larger and partly due to longer piping in the flare system. This can be rationalized by the fact that a larger design rate typically comes from a higher number of blowdown segments, which in turn also comes from a larger facility and hence longer piping.

It is also seen that a larger design rate also results in a higher potential for debottlenecking, especially considering the absolute value of the hidden potential. In relative terms, facility $\mathrm{A}$ and $\mathrm{B}$ are quite similar, with facility $\mathrm{C}$ displaying a higher relative reduction in flare rate from dynamic analysis.

The difference between the steady-state design rate and the peak rate found from dynamic simulations of the emergency depressurization for all investigated facilities is depicted as a function of the steady-state design rate in Figure 12.

In Figure 12, a second-order polynomial regression with a forced intercept at zero is also included which seems to fit the data from the present study quite well. The quadratic dependence of the hidden potential on the steadystate design rate is required to explain the progressively increasing relative reduction in flare tip rate with increasing system design rate. Data on the flare rate reduction potential from Andreasen (2014) and Wasnik et al. (2018) is included for benchmarking of the proposed relationship (not included in the regression analysis). While the data material is relatively sparse, the included results seem to fit the picture of a near-quadratic relationship. The quadratic relationship is to a large extent driven by the results from facility $\mathrm{C}$, and in future investigations more data on large scale facilities shall be 


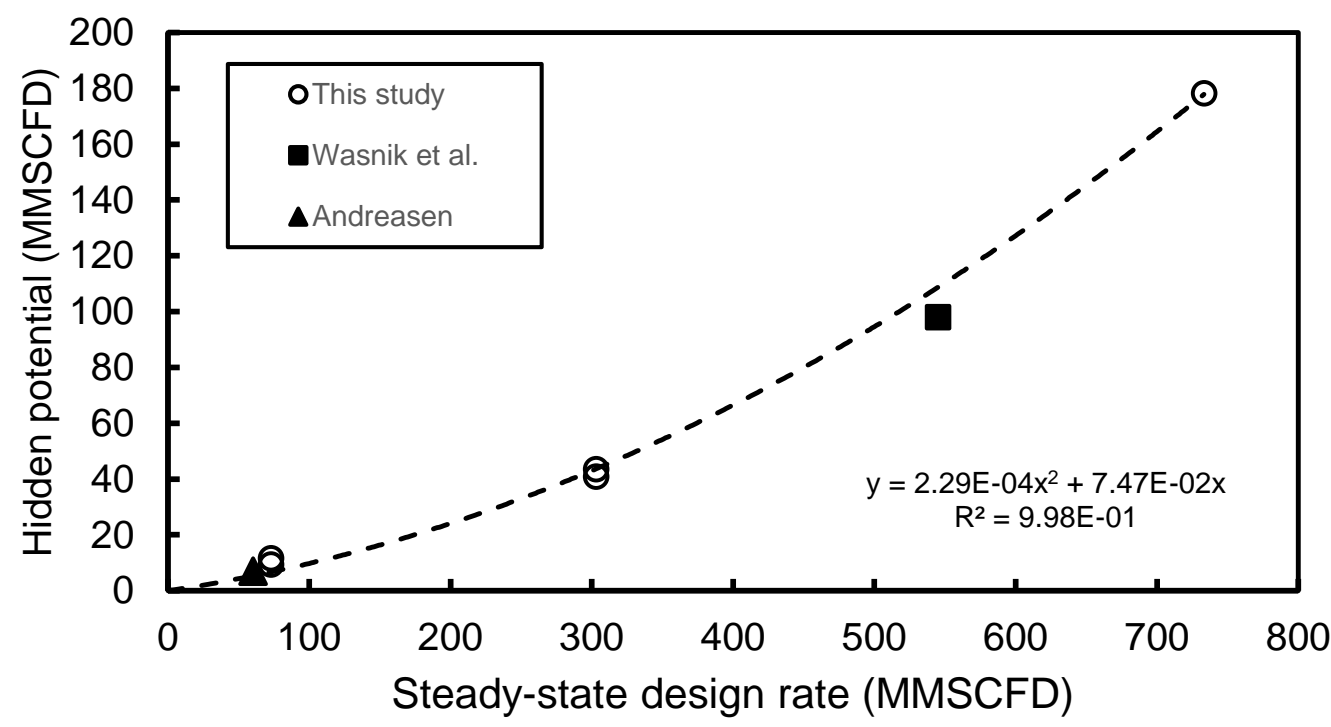

Figure 12: The hidden potential for debottlenecking i.e. difference between the steadystate design flare rate and the peak dynamic simulation rate at the flare tip as a function of steady-state design rate. Comparison with other reported flare rate reductions from dynamic analysis is included for Andreasen (2014) and Wasnik et al. (2018).

analyzed to confirm this relationship.

\section{Conclusion}

In this paper, the possible hidden debottlenecking potential in existing flare systems is analyzed employing dynamic process simulations of an emergency depressurization event. Three different offshore facilities are analyzed, and a comparison is made between steady-state and dynamic simulations. It is generally found that the system backpressure and maximum mass flow rate at the flare tip is significantly reduced compared to the steady-state value. This is due to line-packing effects in the flare system hold-up volume and the fact that the mass flow decreases rapidly as the blowdown segments are depressurized.

By comparing different model complexities, it is also shown that a higher debottlenecking potential can be revealed, if dead ends from non-flow sources are included, since this increases the available hold-up volume. However, the effect is not the dominating one, and can be ignored for more conservative results, especially when fast screening studies are required. 
While both mass rates and back pressure decrease, it is observed that in some locations in the flare system the $\rho \mathrm{v}^{2}$ may actually increase in a dynamic simulation. This can be explained by lower backpressure and hence higher peak velocity due to a lower gas density.

By compiling and analyzing the results for all three facilities, apparently it is found that the larger the facility, the larger the debottlenecking potential. A quadratic relationship between the flare system design rate and the corresponding debottlenecking potential fits the data well. Analysis of more larger systems is required in order to confirm this quadratic relationship.

\section{Abbreviations and symbols}

$\mathrm{D}_{\text {mean }}$ Average diameter of flare network piping

$\mathrm{L}_{\text {net }} \quad$ Total length of piping included in the flare network model

$\mathrm{V}_{\mathrm{KO}}$ Hold-up volume of flare Knock-out drum

$\mathrm{V}_{\text {pipe }}$ Hold-up volume of modeled piping

$\mathrm{V}_{\text {tot }}$ Total hold-up volume of flare system

$C_{p} \quad$ Specific heat capacity at constant pressure

$C_{v} \quad$ Specific heat capacity at constant volume

API American Petroleum Institute

BDV Blowdown Valve

$\mathrm{C}_{\mathrm{V}} \quad$ Valve flow coefficient

CPF Central Processing Facility

DE Dead end

Dyn. Dynamic (simulation)

EDP Emergency Depressurization

FSA Flare System Analyzer

HP High-Pressure 
ID Internal diameter

KO Knock-out

LP Low-Pressure

MW Molecular Weight

NORSOK NORsk SOkkels Konkurranseposisjon

PCV Pressure Control Valve/Spill-over valve

PSV Pressure Safety Valve

SS Steady-state

$\mathrm{T} / \mathrm{T}$ Tan-to-tan

\section{References}

Andreasen, A., 2014. Process design - can we change mindset?, in: Offshore Oil and Gas seminar, 18-22 August 2014, Department of Energy Technology, Aalborg University Esbjerg. doi:10.13140/RG.2.2.13310.33606. oral presentation.

Andreasen, A., Borroni, F., Zan Nieto, M., Stegelmann, C., P. Nielsen, R., 2018. On the Adequacy of API 521 Relief-Valve Sizing Method for Gas-Filled Pressure Vessels Exposed to Fire. Safety 4, 11. doi:10.3390/safety4010011.

Andreasen, A., Eriksen, J.G.I., Stegelmann, C., Lynggaard, H., 2015. Method improves high-pressure settle-out calculations. Oil \& Gas Journal 113, 88-96.

API, 2014. Pressure-relieving and Depressuring Systems, API Standard 521. Technical Report API Standard 521, Sixth Edition, January. American Petroleum Institute.

Biswas, S., Fischer, B.J., 2017. Application and validation of the api analytical fire method in pressure-relieving and depressuring systems. Journal of Loss Prevention in the Process Industries 50, $154-164$. doi:10.1016/j.jlp.2017.09.008. 
Bjerre, M., Eriksen, J.G.I., Andreasen, A., Stegelmann, C., Mandø, M., 2017. Analysis of pressure safety valves for fire protection on offshore oil and gas installations. Process Safety and Environmental Protection 105, 60-68. doi:10.1016/j.psep.2016.10.008.

Borden, G. (Ed.), 1998. Control Valves - Practical Guides for Measurement and Control. Instrument Society of America.

Chakrabarty, A., Mannan, S., Cagin, T., 2016. Multiscale Modeling for Process Safety Applications. Butterworth-Heinemann, Boston. doi:10.1016/B978-0-12-396975-0.05001-4.

Chen, F.F.K., Jentz, R.A., Williams, D.G., 1992. Flare System Design: A Case for Dynamic Simulation, in: Offshore Technology Conference, pp. 421-430. doi:10.4043/6919-MS.

Firth, B., 2016. Unpicking Oversimplification: Relief and Flare Studies for Complex Plant using Dynamic Process Modelling, in: Hazards 26, Institution of Chemical Engineers Symposium Series, pp. 1-12.

Hankinson, R.W., Thomson, G.H., 1979. A new correlation for saturated densities of liquids and their mixtures. AIChE Journal 25, 653-663. doi:10.1002/aic.690250412.

Haque, A., Richardson, S., Saville, G., Chamberlain, G., 1990. Rapid depressurization of pressure vessels. Journal of Loss Prevention in the Process Industries 3, 4 - 7. doi:10.1016/0950-4230(90)85015-2.

Haque, M.A., Richardson, M., Saville, G., 1992. Blowdown of pressure vessels. Pt. I: Computer model. Trans. IChemE B 70, 3-9.

ISA, 1995. Flow Equations for Sizing Control Valves, ANSI/ISA S75.01 Standard, ISA-S75.01-1985 (R 1995). Instrument Society of America.

ISO, 2006. Petroleum, petrochemical and natural gas industries - Pressurerelieving and depressuring systems . Technical Report ISO 23251:2006(E). International Organization for Standardization.

Jo, Y.P., Cho, Y., Hwang, S., 2020. Dynamic analysis and optimization of flare network system for topside process of offshore plant. Process Safety and Environmental Protection 134, 260 - 269. doi:10.1016/j.psep.2019.12.008. 
Leporini, M., D’Alessandro, V., Mancini, E., Terenzi, A., Marchetti, B., Giacchetta, G., Grifoni, R.C., 2018. A new integrated approach to study the thermal and mechanical response of vessels subject to a safe blowdown process. Journal of Loss Prevention in the Process Industries 53, $103-114$. doi:10.1016/j.jlp.2017.06.003. risk Analysis in Process Industries: State-ofthe-art and the Future.

NORSOK, 2014. Process System Design, NORSOK Standard, P002, Edition 1, August 2014. Technical Report. NORSOK. URL: wWw. standard.no/petroleum.

Nougués, J., Gruber, D., Leipnitz, D.U., Sethuraman, P., Alos, M., Brodkorb, M., 2010. Are there alternatives to an expensive overhaul of a bottlenecked flare system? Petroluem Technology Quarterly Q1, 94.

Peng, D.Y., Robinson, D.B., 1976. A new two-constant equation of state. Industrial \& Engineering Chemistry Fundamentals 15, 59-64. doi:10.1021/i160057a011.

Richardson, S.M., Saville, G., 1992. Blowdown of vessels and pipelines, in: Institution of Chemical Engineers Symposium Series, pp. 195-209.

Shell, 2010. Design of pressure relief, flare and vent systems, Shell DEP 80.45.10.10. Shell.

Singh, A., Li, K., Lou, H.H., Hopper, J., Golwala, H., Ghumare, S., Kelly, T., 2007. Flare minimisation via dynamic simulation. International Journal of Environment and Pollution 29, 19-29. doi:10.1504/IJEP.2007.012794.

Total, 2012. GENERAL SPECIFICATION, PROCESS GS EP EP 103, Process Sizing Criteria, rev. 7. TOTAL.

Wasnik, R., Singh, H., Kamal, F.R., Takieddine, O.H., $2018 . \quad$ Debottlenecking of existing flare system for facility up-gradation using dynamic simulation approach - case study, in: Abu Dhabi International Petroleum Exhibition \& Conference, 12-15 November, Abu Dhabi, UAE, Society of Petroleum Engineers. pp. 1-12. doi:10.2118/192750-MS. paper SPE-192750-MS. 